\title{
Acute Toxicity Bioassays of Cadmium and Mercury on the Juveniles of Asian seabass Lates calcarifer (Bloch)
}

\author{
V. Mohan Raj1*, A. R. Thirunavukkarasu'2, M. Kailasam², \\ M. Muralidhar ${ }^{2}$, R. Subburaj ${ }^{2}$ and P. Stalin ${ }^{2}$ \\ ${ }^{1}$ Assistant Professor, Sir Theagaraya College, PG \& Research Department of Zoology, \\ Chennai, Tamil Nadu, India, drvmraj@gmail.com \\ ${ }^{2}$ Central Institute of Brackishwater Aquaculture, 75, Santhome High Road, R.A. Puram \\ Chennai - 600 028, Tamil Nadu, India; artarasu@yahoo.com, kailu66@hotmail.com, \\ muralichintu@rediffmail.com, rsuburaj@hotmail.com, stal2kan@gmail.com
}

\begin{abstract}
The present study was undertaken to investigate the acute toxicity of two heavy metals cadmium and mercury in the juveniles of Asian seabass Lates calcarifer (Bloch) which is considered as an important candidate fish species for brackishwater and freshwater aquaculture. Experiments for the bioassay were performed in static bioassay test condition according to the standard guidelines. The experiment was carried out in the FRP tanks under laboratory condition. The behavioral changes in the fish were observed for all test concentrations of both cadmium and mercury. Median lethal concentrations $\left(\mathrm{LC}_{50}\right.$ ) were calculated for $24 \mathrm{~h}, 48 \mathrm{~h}, 72 \mathrm{~h}$ and $96 \mathrm{~h}$ by probit analysis. The $\mathrm{LC}_{50}$ values for $96 \mathrm{~h}$ and $95 \%$ confidence intervals for the juveniles of seabass L. calcarifer showed $6.08 \mathrm{ppm}$ for cadmium and $1.03 \mathrm{ppm}$ for mercury. Furthermore, the exposed specimens showed dose and duration dependent, abnormal behavior and hyperactivity. Mercury indicated more toxic than cadmium for seabass L. calcarifer.
\end{abstract}

Keywords: Lates calcarifer, Heavy Metals, Cadmium, Mercury.

\section{Introduction}

Advancement of urbanization and industrialization has leads to drastic increase on the environmental contamination. The demand for meeting nutritional and livelihood security of the growing millions of people has forced the mankind for intensification of agriculture and aquaculture. Pollution of aquatic environment by heavy metals is a world-wide problem due to the persistency and continuing accumulation of metals in the environment [1]. Generally, the effect of heavy metals on aquatic organisms ranges from slight reduction in growth rate to death; severe imbalances in concentration can lead to death, while marginal imbalances may cause poor health and retarded growth [2].

Among the heavy metals, cadmium and mercury are considered as potential and cause different effects on aquatic environment especially to the fish species [3]. In recent years, cadmium is widely used in mining, metallurgical operations, electroplating industries, manufacturing vinyl plastics, electrical contacts, metallic and plastic pipes and also in pigment manufacturing, plastic stabilizer and batteries. The use of cadmium in agriculture as fertilizers, either as chemicals or sludge from sewage plants and the use of cadmium containing pesticides might also contribute to the possible contamination

* Corresponding author:

V. Mohan Raj (drvmraj@gmail.com) 
in water bodies [4] Cadmium concentration rise is predominant in the environment due to continuous discharge of industrial wastes and domestic sewage wastes so it is well known as a highly toxic pollutant [5]. The toxic effects of cadmium have been reported by various workers in different types of fish species $[6,7,8]$. Mercury has many industrial uses, such as in the manufacture of plastics, chlorine, caustic soda and caustic potash, and agricultural fungicides. These industries are responsible for the discharge of mercury and its compounds into the aquatic environment. Inorganic mercury is the most common form of the metal released in the environment by industries, presenting a stronger acute effect on aquatic organisms than that of the organic form of mercury [9]. Mercury concentrations in fish have been estimated in different parts of the world and its toxicity to fishes have been very well documented $[10,11,12]$.

Toxicological studies of the pollutants upon aquatic organisms are very important from the point of environmental consequences. Fishes are often forced to encounter in the highly contaminated water especially in areas where the dilution rate of waste water is low. Fish species can be used as test organism because, it is the best understood aquatic species and can be a front line indicator of suspected aquatic pollutants such as metals [10]. Acute toxicity studies can help to detect, evaluate and abatement of pollution by providing reliable estimates of safe concentration, from which water quality criteria can be derived [13]. The best method of acute toxicity testing is by the determination of $\mathrm{LC}_{50}$ or $\mathrm{LD}_{50}$, which represents the amount of a toxicant either in the form of Lethal Concentration (LC) or Lethal Dose (LD) showing $50 \%$ kill of the population of the test animal within fixed period of time [14].

The present study was conducted to determine the acute toxicity of heavy metals cadmium and mercury by static bioassay procedure exposing the fish, Asian seabass Lates calcarifer. Asian seabass is considered as an important candidate fish species for brackishwater aquaculture [15]. Seabass is a euryhaline fish and extensively cultured both in earthen ponds and open cages under marine, brackishwater and freshwater conditions [16]. In India, various research programs have been undertaken on seabass in order to evaluate the rearing techniques $[17,18]$ and also the interest to farm seabass is increased day by day. However, various stages of this important fish during the course of their life cycle have to experience variety of environmental contaminants in the aquatic ecosystem. Therefore, the present investigation was taken to estimate the acute toxicity of the heavy metals cadmium and mercury.

\section{Materials and Methods}

\subsection{Test Organism and Acclimatization}

Healthy hatchery reared juvenile Asian seabass L. calcarifer with mean total length of $8.06 \pm 0.05 \mathrm{~cm}^{-1}$ and mean total weight of $6.38 \pm 0.14 \mathrm{gm}^{-1}$ were obtained from the Central Institute of Brackishwater Aquaculture, (CIBA) experimental station, Muttukadu near Chennai, Tamil Nadu, India. They were maintained for a period of one week in a 10 ton capacity rectangular Reinforced Concrete Cement (RCC) tanks for acclimatization prior to the experimental condition. During this period, they were fed with minced fish meat of Tilapia and Sardines @ 3\% body weight.

\subsection{Preparation of Test Chemicals}

Stock solution of cadmium chloride monohydrate $\left(\mathrm{CdCl}_{2}\right.$. $\mathrm{H}_{2} \mathrm{O}$, Merck with the purity of 99.9\%) was prepared for cadmium with deionized water. Test solutions were made by diluting the stock solution in exposure tanks seawater to produce desired cadmium concentration for each treatment. Likewise, for mercury $\left(\mathrm{HgCl}_{2} \cdot \mathrm{H}_{2} \mathrm{O}\right)$ mercuric chloride monohydrate (Merck with purity of 99\%) was prepared with deionized water. Test solutions were made by diluting the stock solution to produce desired mercury concentration for each treatment. Seawater without addition of chemical was used as control.

\subsection{Preliminary Tests}

The exploratory range of concentration of test chemicals was determined with a series of range finding experiments [14]. Thereafter, definitive acute toxicity bioassays were conducted by exposing fish to different concentrations of cadmium and mercury for $96 \mathrm{~h}$. A set of 10 healthy juvenile seabass were transferred to experimental container of 100 lt. capacity Fibre Reinforced Plastic (FRP) tanks, exposed to each heavy metal concentrations of $2,4,6,8,10$ and $12 \mathrm{ppm}$ of cadmium and a set of another 10 fishes were exposed to the concentrations of $0.6,0.8$, $1.0,1.2,1.4$ and $1.6 \mathrm{ppm}$ of mercury. In control tank, fishes were maintained with filtered seawater. All the treatments were conducted in triplicates. Water temperature was $28.5 \pm 1.5^{\circ} \mathrm{C}$; average $\mathrm{pH}$ was 6.5 , Dissolved oxygen ranged from 5.5 to $6.5 \mathrm{mgl}^{-1}$, Ammonia ranged 
from 0.5 to $0.8 \mathrm{ppm}$, Nitrite ranged from 0.4 to $0.6 \mathrm{ppm}$ respectively. Salinity was maintained at $25 \pm 0.5 \mathrm{ppt}$ throughout the experiment. Test medium was not renewed during the assay and no food was provided to the animals. The toxicity tests were conducted following the static bioassay protocols described by Sprague [19].

Mortality of seabass was recorded at regular time intervals of $24,48,72$ and $96 \mathrm{~h}$, during the period of experiment, dead fishes were removed immediately from the experimental tanks. Fish behavior was also observed during exposure of different concentrations of heavy metals. $\mathrm{LC}_{50}$ values were calculated from the data obtained in acute toxicity bioassays as described by Finney [20]. Probit analysis was carried out by SPSS computer statistical software package. Slope (s) function and confidential limit (Upper confidential limit and lower confidential limit) of the regression line with correlation co efficient were calculated. Based on the acute toxicity test, the $96 \mathrm{~h} \mathrm{LC}_{50}$ value was calculated for both the heavy metals cadmium and mercury.

\section{Results}

\subsection{Fish Behavior}

In control tank, experimental organisms exhibited normal behavior and swimming patterns without any mortality. Fish exposed to different concentrations of heavy metals both cadmium and mercury showed abnormal behavior. At the start of exposure, for both the metals fishes were alert, stopped swimming and remained static position in response to the sudden changes in the surrounding environment. After some time, they tried to avoid the toxic water with fast swimming and jumping. Faster opercular activity was observed as surfacing and gulping of air. In tanks with higher concentrations of 10 and $12 \mathrm{ppm}$ of cadmium, 1.4 and $1.6 \mathrm{ppm}$ of mercury, the fishes swam erratically with jerky movements and hyper excitability. Fins became hard and stretched, due to stretching of body muscles. They secreted copious amounts of mucus continuously, body pigmentation decreased with blackening noticed on the body surface. Ultimately, fish lost balance, became exhausted, lost consciousness, and became lethargic. Lastly, they remained in a vertical position for a few minutes with the anterior side or terminal mouth up near the surface of water, trying to gulp the air and the tail in a downward direction. Soon they settled in the bottom of the tank and after some time their bellies turned upward and the fish died.
Figure 1 depicts the relationship between concentration of test chemical and percentage fish mortality. It clearly showed that high rate of mortality could be noticed in higher concentrations of heavy metals. No mortality was observed during the experimental periods in control. Figure 1 shows that as the concentration of the chemical increased, fish mortality also increased, and thereby indicating direct relationship on higher incidents of mortality with higher concentrations of test chemicals. Results on the $\mathrm{LC}_{50}$ values for cadmium and mercuric at $96 \mathrm{~h}$ of exposure were presented in Table 1 and 2 . The $\mathrm{LC}_{50}$ value for $\mathrm{Cd}$ at $96 \mathrm{~h}$ was $6.08 \mathrm{ppm}$ and similarly, the $\mathrm{LC}_{50}$ value for $\mathrm{Hg}$ was $1.03 \mathrm{ppm}$. It can be also stated from Fig. 1 that mercury was found to be more toxic to seabass $L$. calcarifer than cadmium under similar test conditions. A smaller concentration of $\mathrm{Hg}$ than $\mathrm{Cd}$ could cause high mortality in fishes.

\section{Discussion}

Estimation of $\mathrm{LC}_{50}$ of heavy metals is so important with reference to particular fish species. According to Brongs and Mount [21], the application of the $\mathrm{LC}_{50}$ value is the most highly reliable test for assessing the potential adverse effects of chemical contaminants to aquatic life. Bryan [22], has listed a series of factors influencing toxicity of heavy metals in solution, these include the dissolved form of metals, the presence of other metals and factors influencing the physiology and behavior of the organism. In the present study, fishes exposed to cadmium and mercury were under stress condition for the entire bioassay period and showed erratic, unbalanced swimming movements and tended to surface more frequently than the fish in control medium. Similar observations were made earlier by Narges et al. [23] in the fish Chanos chanos and Nagarajan et al [24] in the fish Therapon jarbua. In the present study L. calcarifer exhibited characteristic avoidance behavior by rapid and erratic swimming with jerky movements and hyper-excitability such type of changes were also observed in Channa punctata after cadmium toxification [8]. Altered movements occurred in the present study was in agreement with Agarwal [25], who has also reported similar abnormal behavior in C. punctatus exposed to mercury Likewise, in the fish Ambassis commersoni exposed to cadmium abnormal behavior and altered movements are observed by Pragatheeswaran et al. [26]. It is reported that heavy exudation of mucus over the body of the fish and dispigmentation are attributed 
(A)

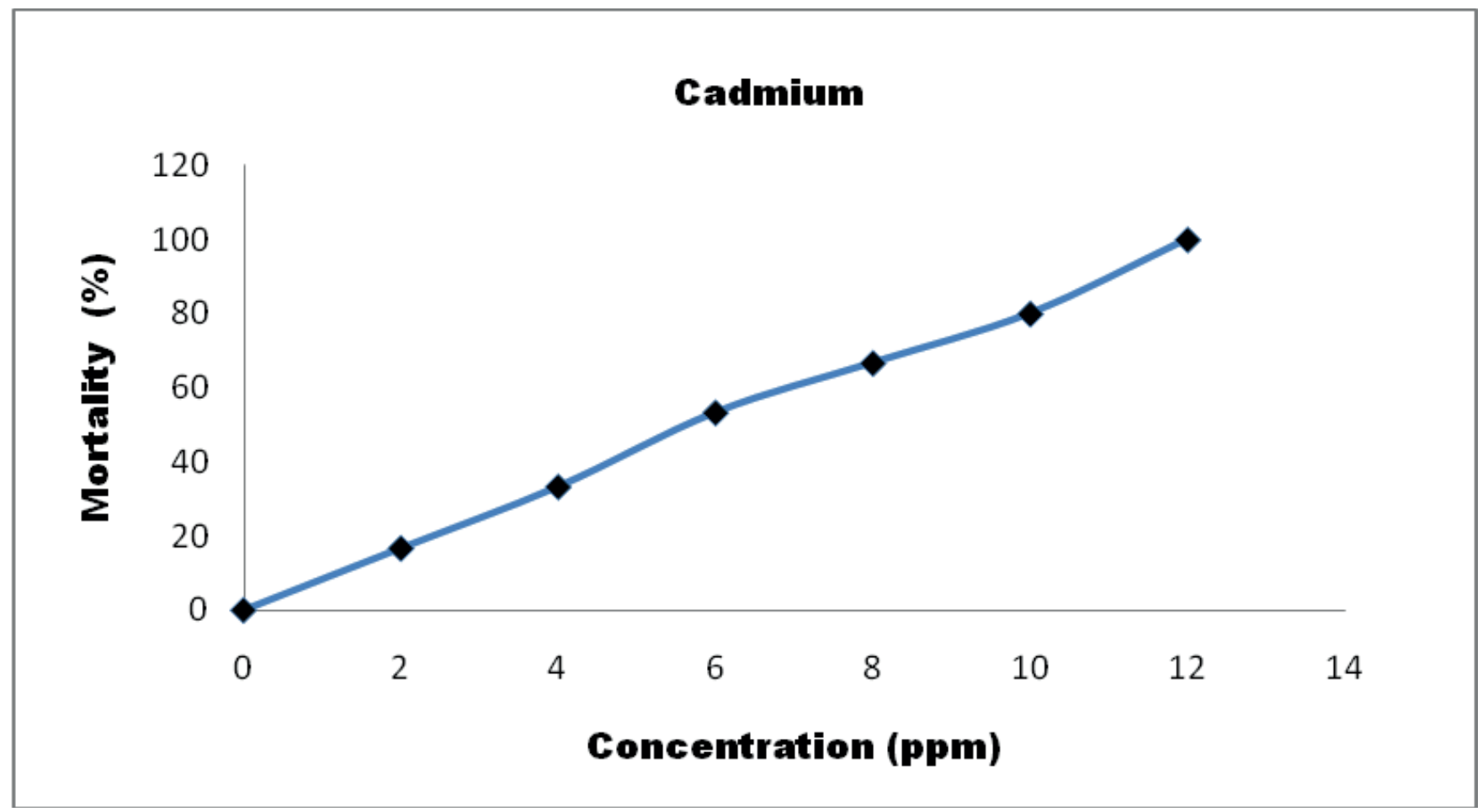

(B)

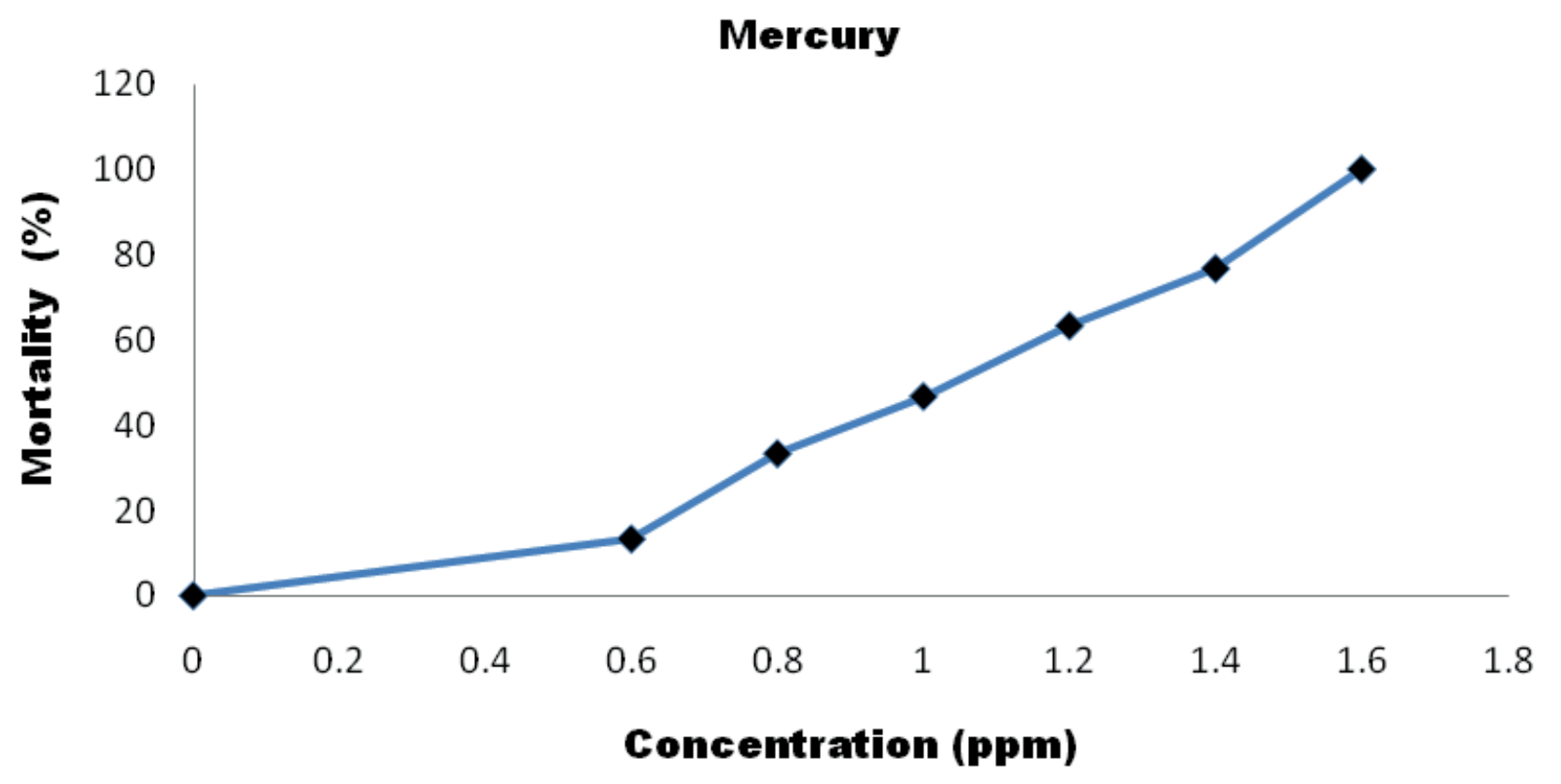

Figure 1. Plot of probits and predicted regression line of (A): Cadmium and (B): Mercury. 
Table 1. $\mathrm{LC}_{50}$ value of cadmium with lower and upper (95\%) confidence limits

\begin{tabular}{lccr}
\hline \multirow{2}{*}{$\begin{array}{l}\text { Exposure } \\
\text { periods }(\mathrm{Hrs})\end{array}$} & $\begin{array}{c}\mathrm{LC}_{50} \text { value } \\
(\mathrm{ppm})\end{array}$ & \multicolumn{2}{c}{$\begin{array}{c}\text { 95\% Confidence } \\
\text { Limit }\end{array}$} \\
\cline { 3 - 4 } & & Lower & Upper \\
\hline 24 & 11.741 & 10.227 & 14.439 \\
48 & 7.781 & 6.928 & 8.756 \\
72 & 6.641 & 5.834 & 7.476 \\
96 & 6.084 & 5.322 & 6.846 \\
\hline
\end{tabular}

Table 2. LC $_{50}$ value of mercury with lower and upper (95\%) confidence limits

\begin{tabular}{lccc}
\hline \multirow{2}{*}{$\begin{array}{l}\text { Exposure } \\
\text { periods (Hrs) }\end{array}$} & \multirow{2}{*}{$\begin{array}{c}\text { LC }_{50} \text { value } \\
(\mathrm{ppm})\end{array}$} & \multicolumn{2}{c}{$\begin{array}{c}\text { 95\% Confidence } \\
\text { Limit }\end{array}$} \\
\cline { 3 - 4 } & & Lower & Upper \\
\hline 24 & 1.498 & 1.377 & 1.695 \\
48 & 1.197 & 1.112 & 1.284 \\
72 & 1.061 & 0.981 & 1.411 \\
96 & 1.031 & 0.950 & 1.111 \\
\hline
\end{tabular}

to dysfunction of the endocrine or pituitary gland under toxic stress, causing changes in the number and area of mucus glands and chromatophores [27]. The preceding behavioral abnormalities of the fish and subsequent death imply that the toxic effect is mediated through the disturbed nervous or cellular enzyme system affecting the respiratory function and nervous system, which involves control of almost all vital activities, as many earlier studies have demonstrated that heavy metals have been shown to affect $\mathrm{Na}^{2+}-\mathrm{K}^{2+}$-ATPase in the brain [28]. Likewise, the cause of death of $L$. calcarifer from exposure to cadmium and mercury is perhaps toxic actions on the biochemical processes related to cellular metabolic pathways and other inclusions.

In this study, the $96 \mathrm{~h}_{50}$ values recorded for the two heavy metals cadmium and mercury can be compared very well with the earlier results of many researchers. The $96 \mathrm{~h}$ $\mathrm{LC}_{50}$ values of cadmium exposed to Channa punctatus was 11.2 ppm reported by Sastry, and Shukla [29]. Whereas, Ramesha et al. [6], reported the $\mathrm{LC}_{50}$ value of cadmium for the fish Cyprinus carpio, was $4.5 \mathrm{ppm}$. In the case of Tinca tinca the $\mathrm{LC}_{50}$ value was $6.5 \mathrm{ppm}$ of cadmium noted by Altindag et al. [30] and in Boleophthalmus dussmieri the $96 \mathrm{~h} \mathrm{LC}_{50}$ value for cadmium was $6.5 \mathrm{ppm}$ studied by Manoj and Ragothaman [31], which is similar to the findings of the present study. However, in the fish Mystitus viltatus higher $\mathrm{LC}_{50}$ value for cadmium was estimated with $17.94 \mathrm{ppm}$ reported by Rao, and Manjula [32]. Similarly, the $96 \mathrm{LC}_{50}$ values of fish vary from species to species and from metal to metal [33]. While Agarwal [25] reported the $96 \mathrm{~h} \mathrm{LC}_{50}$ value for mercury in the fish Channa punctatus with 2.11 ppm. However, in the fish Cyprinus carpio $\mathrm{LC}_{50}$ value was $0.5 \mathrm{ppm}$ for mercury recorded by Sivaramakrishnan, and Radhakrishnan [34]. In the case of Rasbora daniconius, 0.80 ppm was reported as $\mathrm{LC}_{50}$ value for mercury by Gupta and

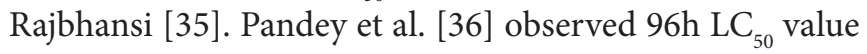
for mercury as $1.21 \mathrm{ppm}$ in the fish Channa punctatus. Similarly, in Cirrhinus mrigala the $\mathrm{LC}_{50}$ value for mercury was 1.11 ppm quoted by Gupta and Kumar [37] and in the fish Tinca tinca the $\mathrm{LC}_{50}$ value was $1.0 \mathrm{ppm}$ for mercury noted by Altindag et al. [30], which is in agreement with the results of the present study. Whereas, the $\mathrm{LC}_{50}$ value of $2.0 \mathrm{ppm}$ mercury was observed in the fish Boleophthalmus dussmieri by Manoj and Ragothaman [31].

In the present investigation, the median lethal concentration $\left(\mathrm{LC}_{50}\right.$ for $96 \mathrm{hrs}$ ) of cadmium in L. calcarifer was determined to be $6.08 \mathrm{ppm}$ (Table 1) and for mercury 1.03 ppm (Table 2). Leblond, and Hontela [38] studied the acute toxicity of mercury, zinc and cadmium in rainbow trout and reported that the fish was more susceptible to mercury, followed by that of zinc and cadmium. This is in agreement with the present study where mercury was indicated as more toxic (1.03 ppm) metal than that of cadmium (6.08 ppm) in L. calcarifer. It is widely accepted that the stress response as a whole is characterized by physiological changes. These changes tend to be similar for stressors and could be as varied as anesthesia, flight, forced swimming, disease treatments, handling, scale loss, or rapid temperature change [39]. A study by Bonga [40] showed that stressor increases the permeability of the surface epithelia, including the gills to water and ions and thus induces hydro mineral disturbances. Acute toxicity studies were the very first step in determining the water quality requirements of fish. These studies obviously reveal the toxicant concentrations $\left(\mathrm{LC}_{50}\right)$ that cause fish mortality even at short exposure. Therefore, studies demonstrating the sensitivity of xenotoxic effects of heavy metals in aquatic organisms, particularly in fish are needed. Thus, it can be concluded from the present study that the fish seabass $L$. calcarifer was highly sensitive to mercury and sensitive to cadmium and their mortality rate is dose dependent. 


\section{Acknowledgements}

The authors thank Dr. A. G. Ponniah, Director, Central Institute of Brackishwater Aquaculture, Chennai, India, for providing necessary infrastructure facilities. We also appreciate Mr. G. Thiagarajan and Mr. K. Karaiyan for their help.

\section{References}

1. Hyun S, Lee T, and Park Y H (2006). The effects of metal distribution and anthropogenic effluents on the benthic environment of Gwangyang Bay, Korea, Marine Pollution Bulletin, vol 52(1), 113-120.

2. Joel O F, and Amajuoyi C A (2009). Evaluation of the effect of short-term cadmium exposure on brackish water shrimp Palaemonetes africanus, Journal of Applied Sciences and Environmental Management, vol 13(4), 23-27.

3. Olsson P E (1998). Disorders associated with heavy metal pollution, Fish Diseases and Disorders (Non-infectious Disorders), Edn. Leatherland JE and Woo PTK, CABI International, UK, vol 2, 105-131.

4. Goering P L, Waalkes M P, and Klaaseen C D (1995). Toxicology of cadmium, Ed. Goyer, RA and Cherian MG, Toxicology of Metals Biochemical aspects, Springer, Berlin, 189-214.

5. Wright D A, and Welbourn P M (1994). Cadmium in the aquatic environment: a review of ecological, physiological and toxicological effects on biota, Environmental Reviews, $\operatorname{vol} 2(2), 187-214$.

6. Ramesha A M, Gupta T R C, and Lingadhal C (1998). Toxic effect of mercury and cadmium to the cadmium pretreated life stages of common carp Cyprinus carpio (Linn.), Pollution Research, vol 17(4), 403-406.

7. Pandey A, Kunwar G K, and Munshi J S D (1990). Integumentary chromatophores and mucus glands of fish as indicator of heavy metal pollution, Journal Freshwater Biology, vol 94, 117-121.

8. Tiwari N S M, Nagpure D N Saksena, Singh S P R K, Kushwaha B, and Lakra W S (2011). Evaluation of acute toxicity levels and ethological responses under heavy metal cadmium exposure in freshwater teleost, Channa punctata (Bloch), International Journal of Aquatic Science, vol 2(1), 36-47.

9. Sunderland E M, and Chimera G L (2000). An inventory of historical mercury emissions in Maritime Canada: Implications for present and future contamination, Science of The Total Environment, vol 256(1), 39-57.

10. Vieira L R, Gravato C, Soares A, Margado F, and Guilhermino L (2009). Acute effects of copper and mercury on the estuarine fish Pomatoschistus microps: Linking biomarkers to behavior, Chemosphere, vol 76(10), 1416-1427.
11. Pandey S, Kumar R Sharma S, Naghpure N S, Srivasta S K, and Verma M S (2005). Acute toxicity bioassays of mercuric chloride and malathion on air-breathing fish, Channapunctatus, Ecotoxicology and Environmental Safety, vol 61(1), 114-120.

12. Heydayati A, Safaheih A Savari A, and Marammazi J G (2010). Detection of mercury chloride acute toxicity in Yellow fin sea bream (Acanthopagrus latus), World Journal of Fish and Marine Sciences, vol 2(2), 86-92.

13. Absunullah M, Negilsky D S, and Mobley M C (1981). Toxicity of zinc, cadmium and copper to shrimp Callianassa australiensis effects of individual metals, Marine Biology, vol 64(3), 299-304.

14. APHA/AWWA/WPCF (1998). Standard Methods for the Examination of Water and Wastewater. $20^{\text {th }}$ edn. Am. Public Health Assoc., New York.

15. Thirunavukkarasu A R, Abraham M, and Kailasam M (2004). Handbook of seed production and culture of Asian seabass, Lates calcarifer (Bloch), CIBA, Bulletin, Chennai, India, vol $18(2), 1-58$

16. Barlow C G, Rodgers L J Palmer P J, and Longhurst C J (1993). Feeding habits of hatchery reared barramundi, Lates calcarifer (Bloch) fry, Aquaculture,vol 103(2), 131-143.

17. Kailasam M, Thirunavukkarasu A R Selvaraj S, and Stalin P (2007). Effect of delayed initial feeding on growth and survival of Asian seabass, Lates calcarifer (Bloch), Aquaculture, vol 271(1-4), 298-306.

18. Kailasam M, Thirunavukkarasu A R Sundaray J K, Mathew A, Subburaj R, Thiagarajan G, and Karaiyan K (2006). Evaluation of different feeds for nursery rearing of Asian sea bass, Lates calcarifer (Bloch), Indian Journal of Fisheries, vol 53(2), 185-190.

19. Sprague J B (1969). Measurement of pollutant toxicity to fish. I. Bioassay method for acute toxicity, Water Research, $\operatorname{vol} 3(11), 793-821$.

20. Finney D J (1971). Probit analysis, $3^{\text {rd }}$ edn., Cambridge University Press, New York.

21. Brongs W A, and Mount D I (1978). Introduction to a discussion of the use of aquatic toxicity tests for evaluation of the effects to toxic substances, Chapter 2, Estimating the hazard of chemical substances to aquatic life, ASTM International, STP 657, 15-26.

22. Bryan GW (1976). Some aspects of heavy metal tolerance in aquatic organisms. (ed. A.P.M. Lockwood), Effects of pollutants on aquatic organisms, Cambridge University Press, Cambridge, England, 7-34.

23. Narges A B, Ahmad S, Mortazavi M S, and Zolgharnein H (2010). Acute toxicity of cadmium chloride $\left(\mathrm{CdCl}_{2} \cdot \mathrm{H}_{2} \mathrm{O}\right)$ on Chanos chanos and their behavior responses, World Journal of Fish and Marine Science, vol 2(6), 481-486. 
24. Nagarajan N, Devi V J Devi C A, and Kumaraguru A K (2009). Genotoxicity Assessment of Mercuric Chloride in the Marine Fish Theraponjarbua. Environment Asia, vol 2(2), 50-54.

25. Agarwal S K (1991). Bioassay evaluation of acute toxicity levels of mercuric chloride to an air-breathing fish Channa punctatus (Bloch) mortality and behavior study, Journal of Environmental Biology, vol 12, 99-106.

26. Pragatheeswaran V, Loganathan $P$ Natarajan $R$, and Venugopalan V K (1987). Cadmium induced vertebral deformities in an estuarine fish, Ambassis commersoni, Proceedings: Animal Sciences, vol 96(4), 389-394.

27. Othman S, Nadzifah Y, and Ahmad A K (2010). Toxicity of copper and cadmium to freshwater fishes, World Academy of Science, Engineering and Technology, vol 65, 869-871.

28. Verma S R, Jain M, and Tonk I P (1983). In vivo effects of mercuric chloride on tissue ATPase of Notopterus notopterus, Toxicology Letters, vol 16(3-4), 305-309.

29. Sastry K V, and Shukla V (1993). Uptake and distribution of cadmium in tissues of Channa punctatus, Journal of Environmental Biology, vol 14(2), 137-142.

30. Altindag A, and Shah S L (2005). Effects of heavy metal accumulation on the 96-h $\mathrm{LC}_{50}$ values in Tench Tinca tinca L., Turkish Journal of Veterinary and Animal Sciences, vol 29, 139-144.

31. Manoj G K, and Raghothaman (1999). Mercury, copper and cadmium induced changes in the total protein level muscle tissue of an edible estuarine fish Boleophthalamus dessumieri, (CUV), Journal of Environmental Biology, vol 20(3), 231-234.

32. Rao L M, and Patnaik R M S (1997). Acute toxicity of Zn, $\mathrm{Pb}$ and $\mathrm{Cd}$ in the freshwater catfish Mystus vittatus (Bloch), Indian Journal of Fisheries, vol 44(4), 55-64.
33. Gill T S, and Pant J C (1985). Erythrocytic and leukocytic responses to cadmium poisoning in fresh water fish, Puntius conchonius, Environmental Research, vol 30(2), 372-373.

34. Sivaramakrishnan B, and Radhakrishnan K (1998).Impact of sublethal concentration of mercury on nitrogen metabolism of the freshwater fish, Cyprinus carpio (Linaeus), Journal of Environmental Biology, vol 19(2), 111-117.

35. Gupta A K, and Rajbanshi V K (1996). Mercury poisoning Architectural changes in the gill of Rasbora daniconius (Ham.), Journal of Environmental Biology, vol 16(1), 33-36.

36. Pandey S, Kumar R Sharma S, Nagpure N S, Srivastava S K, and Verma M S (2005). Acute toxicity bioassays of mercuric chloride and malathion on air-breathing fish Channa punctatus (Bloch). Ecotoxicology and Environmental Safety, vol 61(1), 114-120.

37. Gupta A K, and Kumar A (2006). Histopathological lesions in the selected tissues of Cirrhinus mrigala (Ham.) fingerlings exposed to a sublethal concentration of mercury, Journal of Environmental Biology, vol 27(2), 235-239.

38. Leblond V S, and Hontela A (1999). Effects of in vitro exposure to cadmium, mercury, zinc and 1-(2-chlorophenyl)-1(4chlorophenyl)-2, 2-dichloroethane on steridogenesis by dispersed internal cells of rainbow trout (Oncorhynchus mykiss), Toxicology and Applied Pharmacology, vol 157(1), 16-22.

39. Wedenmeyer G A, and McLeay D J (1981). Methods for determining the tolerance of fishes to environmental stressors.Stress and Fish (eds. Pickering AD), Academic Press, London, 247-275.

40. Bonga S E W (1997). The stress response in fish, Physiological Reviews, vol 77(3), 591-625. 